\title{
Research
}

\section{Impact of the GP contract on inequalities associated with influenza immunisation:}

\author{
a retrospective population-database analysis
}

\begin{abstract}
\section{Background}

Influenza immunisation is recommended for all people aged $\geq 65$ years and younger people with particular chronic diseases. The Quality and Outcomes Framework (QOF) has provided new financial incentives for influenza immunisation since 2004
\end{abstract}

\section{Aim}

To determine the impact of the 2004 UK General Medical Services contract on the overall uptake of, and socioeconomic inequalities associated with, influenza immunisation.

\section{Design and setting}

Retrospective general-practice population database analysis in 15 general practices in Scotland, UK.

\section{Method}

Changes in influenza-immunisation uptake for those in at-risk groups between 2003-2004 and 2006-2007 were measured, and variation in uptake examined using multilevel modelling.

\section{Results}

Uptake rose from $67.9 \%$ in $2003-2004$ to $71.4 \%$ in 2006-2007. The largest increases were seen in those aged $<65$ years with chronic disease with uptake rising from $49.6 \%$ to $58.4 \%$, but rates remained considerably lower than in those aged $\geq 65$ years. Differences between practices narrowed (median odds ratio [OR] for two patients randomly selected from different practices: 2.13 (95\% confidence interval $[\mathrm{Cl}]=$ 2.00 to 2.26$)$ in $2003-2004$ versus $1.44(95 \% \mathrm{Cl}=$ 1.40 to 1.49 ) in 2006-2007. However, inequalities in uptake by patient socioeconomic status did not change: adjusted OR for most deprived versus most affluent was $0.75195 \% \mathrm{Cl}=0.70$ to $0.80)$ in $2003-2004$ versus $0.72(95 \% \mathrm{Cl}=0.68$ to 0.76 ) in 2006-2007.

\section{Conclusion}

Overall uptake rose significantly and differences between practices narrowed considerably. However, socioeconomic and age inequalities in influenza immunisation persisted in the first 3 years of the QOF. This contrasts with other ecological analyses, which have concluded that the QOF has reduced inequalities. The impact of financial incentives on inequalities is likely to vary, and some kinds of care may require more targeted improvement activity and support.

\section{Keywords}

contracts; disparities; family practice; influenza (human); pay for performance; socioeconomic factors.

\section{INTRODUCTION}

Influenza infection causes significant morbidity and mortality, particularly among older people and those who are chronically ill.' During years with modest, seasonal influenza activity, GP consultation rates in England for influenza and influenza-like illness range from 20 to 70 per 100000 population per week, with 3000-4000 deaths being attributable to influenza annually. During the epidemic of 1989-1990 this rate peaked at 583 consultations per 100000 population per week, resulting in an estimated 23000 additional deaths due to influenza over this period. ${ }^{2,3}$

Influenza immunisation has been available for almost 60 years. ${ }^{4}$ Although there is continuing debate about its effectiveness in preventing serious illness, ${ }^{4-11}$ it has been recommended since the 1990s for everyone aged $\geq 65$ years, and for younger people in clinical-risk groups, such as those with chronic respiratory and cardiovascular disease, diabetes, asthma requiring regular inhaled corticosteroids, and those receiving immunosuppressive treatment. $^{3}$

Before the 2004 General Medical Services (GMS) contract was implemented, GPs were incentivised to immunise older people on their patient lists through a payment linked to achieving a target percentage $160 \%$ in 2000 , rising to $70 \%$ from 2002) and a fee-forservice payment for younger people at risk. After this, uptake of influenza immunisation in those aged $\geq 65$ years across the UK

M Norbury, BSc(Hons), MSc, MRCGP, DCH DRCOG, GP academic fellow; B Guthrie, PhD, MRCGP, professor of primary care medicine, Quality, Safety and Informatics Research Group N Fawkes, medical student, Ninewells Hospital and Medical School, University of Dundee, Dundee.

Address for correspondence

Michael Norbury, Quality Safety and Informatics Research Group, Clinical and Population Sciences and Education Division, Mackenzie Building, gradually increased. In Scotland, uptake among those aged $\geq 65$ years rose from $65.0 \%$ in $2000-2001$ to $69.0 \%$ in $2002-2003$, compared with $65.4 \%$ and $68.6 \%$ in England. ${ }^{3}$ However, only $25.0 \%$ of younger people in clinical-risk groups were estimated to be immunised in 2004-2005, with large variations both geographically and by disease groups. ${ }^{12,13}$ Additionally, uptake among people living in areas of greater socioeconomic deprivation has been consistently lower than among the affluent. ${ }^{14}$

From April 2004, the Quality and Outcomes Framework (QOF) of the GMS contract additionally incentivised GPs to immunise individuals with coronary heart disease (CHD), stroke and transient ischaemic attack, diabetes, chronic obstructive pulmonary disease (COPD), and asthma. The incentive to immunise people with asthma was removed in April 2006. Existing target payments for older people and fee-for-service payments for younger people at risk were left unchanged.

The uptake of population-level healthimprovement strategies, including immunisation programmes, is known to be socioeconomically patterned. ${ }^{14-18}$ Since its introduction in 2004, several practice-level studies have shown that the QOF appears to have narrowed or abolished differences in practice-level socioeconomic gradients in healthcare quality for blood pressure control in people with hypertension ${ }^{19}$ and for a composite of 48 QOF clinical activity indicators. ${ }^{20}$ However, patient-level analysis

University of Dundee, Dundee DD2 4BF. E-mail: m.norburylacpse.dundee.ac.uk Submitted: 27 October 2010; Editor's response: 19 November 2010; final acceptance 13 December 2010. \section{OBritish Journal of General Practice} This is the full-length article (published online 27 Jun 2011) of an abridged version published in print. Cite this article as: Br J Gen Pract 2011; DOI: 10.3399/bjgp11X583146. 


\section{How this fits in}

Historically, uptake of influenza immunisation has been lower among younger patients and those with greater socioeconomic deprivation. In ecological analysis at practice level, the financial incentives introduced in the 2004 Quality and Outcomes Framework (QOF) appear to reduce socioeconomic inequalities across many targeted measures. In this patientlevel analysis, despite significant increases in the uptake of influenza immunisation between 2003-2004 and 2006-2007, and the narrowing of differences between practices, large inequalities according to socioeconomic status and age persisted. Ecological analyses may be misleading and the impact of the QOF on inequalities for other measures should be examined using patient-level data. Where inequalities are persistent, more targeted quality improvement and support may be required to reduce them.

of care for people with diabetes has shown that inequalities between different ethnic groups have not reduced. ${ }^{21,22}$

The aim of this study was to measure changes in population-level influenzaimmunisation uptake between 2003-2004 (the year before the QOF was introduced) and 2006-2007 (the third year of the contract), and examine how uptake varied by patient characteristics including socioeconomic status and between practices.

\section{METHOD}

Data for patients eligible for influenza immunisation were extracted for the 2003-2004 and the 2006-2007 influenzaimmunisation seasons from a database held by the Primary Care Clinical Informatics Unit at the University of Aberdeen. A total of 315 (31\%) Scottish practices contributed data covering a population that is representative of Scotland as a whole in terms of age, sex, and deprivation. ${ }^{23}$ Patients were defined as eligible for influenza immunisation if they were aged $\geq 65$ years or if they were in one or more specified clinical risk groups at the start of the relevant influenza season (defined as 1 September 2003 or 1 September 2006). Disease indications for immunisation were defined as the presence of CHD, diabetes, stroke or transient ischaemic attack, COPD, or asthma requiring treatment with inhaled corticosteroids /defined as a person coded as having asthma and receiving three or more inhaled corticosteroid prescriptions in the previous 12 months).

For each patient, demographic data lage, sex, and postcode-defined Carstairs deprivation score treated as a pre-defined seven-category variable), ${ }_{1}^{24}$ together with the date of their last influenza immunisation were extracted. Additional practice-level variables were also obtained, namely: list size, defined as quartiles; whether or not the practice was accredited for postgraduate training; and whether the practice held a General Medical Services or Personal Medical Services contract.

Influenza-immunisation uptake was measured for each disease indication and was stratified by whether or not the patient was aged $\geq 65$ years las this is an independent indication); changes between the two seasons were measured. For each of the years, variation in uptake was examined using multilevel logistic regression to examine how receipt of influenza immunisation varied by patient and practice characteristics, and between practices after adjustment for patient variables. For this analysis, a single 'indication' variable was constructed, based on whether or not the patient was aged $\geq 65$ years and the number of chronic conditions the patient had that conferred eligibility for influenza immunisation.

Variation by patient and practice characteristics was examined with multilevel univariate and adjusted odds ratios (ORs). Variation between practices was estimated by calculating intracluster correlation coefficients in the empty models, as well as the median ORs for two patients randomly sampled from different practices in models with patient variables fitted to account for differences in case mix. ${ }^{25}$ All models were fitted with secondorder, penalised, quasi-likelihood estimation, and assumptions of normality of level-two residuals and other model diagnostics checked graphically. Initial data management and analysis was conducted in SPSS (version 17) and multilevel modelling in MLwin (version 2.1).

\section{RESULTS}

On 1 September 2006, 358330 of 1760223 patients in the dataset were eligible for influenza immunisation, compared with 327423 on 1 September 2003. Table 1 shows the percentages of patients receiving immunisation by indication in the 2003-2004 and 2006-2007 influenza seasons. In 2003-2004, uptake among 


\section{Table 1. Percentage of patients receiving influenza immunisation by indication}

\begin{tabular}{|c|c|c|c|}
\hline Indication & $\begin{array}{c}\text { Patients receiving } \\
\text { influenza immunisation } \\
\text { in } 2003-2004 \text { season, } \\
\%(n / n)\end{array}$ & $\begin{array}{c}\text { Patients receiving } \\
\text { influenza immunisation } \\
\text { in } 2006-2007 \text { season, } \\
\%(n / n)\end{array}$ & $\begin{array}{c}\text { Change 2003-2004 } \\
\text { to } 2006-2007 \text {, } \\
\%(95 \% \mathrm{Cl})\end{array}$ \\
\hline Any indication & $67.9(222317 / 327423)$ & 71.4 (255 826/358 330) & 3.5 (3.3 to 3.7 ) \\
\hline$\geq 65$ years, any indication & 72.3 (191 099/264 475) & 75.6 (204 690/270 822) & 3.3 (3.1 to 3.6 ) \\
\hline$<65$ years, any indication & 49.6 (31 218/62 948) & 58.4 (51 136/87 508) & $8.8(8.3$ to 9.4$)$ \\
\hline$\geq 65$ years, no chronic disease & 68.6 (118 392/17 2488) & 70.3 (115 540/164 383) & 1.6 (1.3 to 2.0$)$ \\
\hline$\geq 65$ years, $>1$ chronic disease & 80.8 (17 365/21 494) & 85.6 (25 120/29 336) & 4.8 (4.2 to 5.5$)$ \\
\hline$<65$ years, $>1$ chronic disease & $64.7(4624 / 7145)$ & $74.8(7935 / 10$ 602) & 10.1 (8.7 to 11.5 ) \\
\hline$\overline{\mathrm{CHD}}$ present & $72.6(56493 / 77$ 771) & 79.8 (62 141/77 866) & $7.2(6.7$ to 7.6$)$ \\
\hline$\geq 65$ years, $\mathrm{CHD}$ & & & $4.0(3.6$ to 4.5$)$ \\
\hline$<65$ years, $\mathrm{CHD}$ & & 12) & 13.5 (12.6 to 14.3 ) \\
\hline All stroke/TIA & & & 8.1 (7.4 to 8.8) \\
\hline$\geq 65 y$ & & & to 6.3$)$ \\
\hline$<65$ years, strok & 3 & (8348) & $16.1(14.6$ to 17.7$)$ \\
\hline All diabetes & $73.0(19274$ & 77.0 (40 424/52 487) & $4.0(3.4$ to 4.7$)$ \\
\hline$\geq 65$ years, diabetes & 86.51 & $45 / 27391)$ & $-0.5(-1.2$ to 0.2$)$ \\
\hline$<65$ years, dia & 8) & & (6.5 to 8.5$)$ \\
\hline All active asthm & 51.8 & & 6.0 \\
\hline$\geq 65$ years, active asthma & 83.4 & & 4.5 (3.2 to 5.7$)$ \\
\hline$<65$ years, active asthma & 43.1 (7326/16 978) & $48.6(16118 / 33$ 137) & $5.5(4.6$ to 6.4$)$ \\
\hline All COPD & 71.8 (19 591/27 289) & $79.2(24424 / 30846)$ & $7.4(6.7$ to 8.1$)$ \\
\hline$\geq 65$ years, $\mathrm{COPD}$ & $79.5(14659 / 18430)$ & $84.2(17505 / 20792)$ & $4.7(3.9$ to 5.4$)$ \\
\hline$<65$ years, $\mathrm{COPD}$ & $55.7(4932 / 8859)$ & $68.8(6919 / 10054)$ & 13.1 (11.8 to 14.5$)$ \\
\hline
\end{tabular}

$C H D=$ coronary heart disease. $C O P D=$ chronic obstructive pulmonary disease. $T I A=$ transient ischaemic attack.

eligible patients was consistently higher in people aged $\geq 65$ years compared with younger people, irrespective of chronicdisease indication.

Overall immunisation rates rose by 3.5\% (95\% $\mathrm{Cl}=3.3$ to 3.7 ) in 2006-2007 compared with 2003-2004, with a larger increase of $8.8 \%(95 \% \mathrm{Cl}=8.3$ to 9.4$)$ in those aged $<65$ years compared with $3.3 \%(95 \% \mathrm{Cl}=3.1$ to 3.6$)$ in patients aged $\geq 65$ years. Immunisation rates rose significantly for all groups except people with diabetes aged $\geq 65$ years; for this group there was a nonsignificant fall of $0.5 \%$ lalbeit from the highest 2003-2004 baseline). Rates increased more in patients with a disease indication than in those eligible only by being aged $\geq 65$ years. For patients with a disease indication, rates increased more in younger patients than older patients lalthough from a much lower base). However, although the gap narrowed, large differences between younger and older people with chronic conditions remained in 2006-2007.

Table 2 shows uptake by patient and practice characteristics for both seasons, with univariate and adjusted multilevel ORs. There was significant, large variation by indication and by socioeconomic status. Influenza immunisation increased with the number of chronic conditions for both younger and older people; this gradient was steeper in 2006-2007 than 2003-2004. However, in 2003-2004, younger patients with one or two chronic conditions were less likely to be immunised than older patients with no chronic condition; this remained true in 2006-2007 for younger people with one chronic condition compared with older people with no chronic conditions. Patients living in the most deprived areas were less likely to be immunised than those living in the most affluent in both 2003-2004 (difference $11.7 \%, 95 \% \mathrm{Cl}=10.7$ to 12.7 ) and 2006-2007 (8.2\%, 95\% Cl = 7.3 to 9.1); adjusted ORs were similar in both seasons. Although there were statistically significant differences between males and females, the absolute differences are small (1.2\%).

There was significant variation with regard to immunisation uptake between practices in both seasons, which was not explained by differences in case mix. Patients in larger practices were less likely to be immunised in 2003-2004 than 2006-2007, but differences were smaller in 2006-2007 and not statistically significant in the adjusted model. Other practice-level variables were not significantly associated with influenza-immunisation uptake.

Variation between practices reduced between 2003-2004 and 2006-2007. The intracluster correlation coefficient lthe 
Table 2. Influenza-immunisation uptake for 2003-2004 and 2006-2007 influenza seasons, by patient and practice level variables

\begin{tabular}{|c|c|c|c|c|c|c|}
\hline & $\begin{array}{c}2003-2004 \text { uptake, } \\
\%(n / n)\end{array}$ & $\begin{array}{l}\text { Multilevel univariate } \\
\text { OR }(95 \% \mathrm{CI})\end{array}$ & $\begin{array}{l}\text { Multilevel adjusted } \\
\text { OR }(95 \% \mathrm{Cl})^{\mathrm{a}}\end{array}$ & $\begin{array}{c}\text { 2006-2007 uptake, } \\
\%(n / n)\end{array}$ & $\begin{array}{l}\text { Multilevel univariate } \\
\text { OR }(95 \% \mathrm{CI})\end{array}$ & $\begin{array}{l}\text { Multilevel adjusted } \\
\text { OR }(95 \% \mathrm{CI})^{\mathrm{a}}\end{array}$ \\
\hline \multicolumn{7}{|l|}{ Patient level } \\
\hline \multicolumn{7}{|l|}{ Indication } \\
\hline$\geq 65$ years, no $C D$ & 68.6 (118 392/172 488) & 1.00 & 1.00 & 70.3 (115 540/164 383) & 1.00 & 1.00 \\
\hline$\geq 65$ years, $1 C D$ & 78.5 (55 342/70 493) & $1.78(1.74$ to 1.81$)$ & 1.78 (1.74 to 1.82$)$ & 83.0 (64 030/77 103) & 2.11 (2.06 to 2.15 ) & 2.12 (2.08 to 2.17 ) \\
\hline$\geq 65$ years, $2 \mathrm{CD}$ & $80.6(14605 / 18111)$ & 2.09 (2.01 to 2.19 ) & 2.10 (2.02 to 2.20$)$ & 85.3 (20 267/23 757) & 2.54 (2.45 to 2.64$)$ & 2.57 (2.47 to 2.67 ) \\
\hline$\geq 65$ years, $\geq 3 \mathrm{CD}$ & 81.6 (2760/3383) & 2.18 (1.99 to 2.39$)$ & 2.19 (2.10 to 2.28 ) & $87.0(4853 / 5579)$ & 2.94 (2.71 to 3.18$)$ & 2.98 (2.75 to 3.23 ) \\
\hline$<65$ years, $1 \mathrm{CD}$ & 48.3 (26 594/55 083) & 0.39 (0.39 to 0.40$)$ & $0.40(0.39$ to 0.40$)$ & 56.2 (43 201/76 906) & 0.53 (0.52 to 0.54$)$ & 0.54 (0.53 to 0.55$)$ \\
\hline$<65$ years, $2 \mathrm{CD}$ & 63.7 (3953/6205) & 0.81 (0.76 to 0.85 ) & 0.82 (0.77 to 0.86 ) & 74.2 (6831/9207) & 1.24 (1.18 to 1.10$)$ & 1.26 (1.20 to 1.32$)$ \\
\hline$<65$ years, $\geq 3 \mathrm{CD}$ & 71.4 (671/940) & 1.16 (1.01 to 1.35$)$ & 1.18 (1.02 to 1.37$)$ & $79.1(1104 / 1395)$ & 1.67 (1.46 to 1.90$)$ & 1.70 (1.49 to 1.94$)$ \\
\hline \multicolumn{7}{|l|}{ Sex } \\
\hline Female & $68.4(124223 / 181506)$ & 1.00 & 1.00 & $71.9(140676 / 195$ 521) & 1.00 & 1.00 \\
\hline Male & 67.2 (98 094/14 5917) & 0.94 (0.93 to 0.96$)$ & & 70.7 (115 150/162 809) & $0.94(0.93$ to 0.96$)$ & 0.96 (0.94 to 0.97) \\
\hline \multicolumn{7}{|c|}{ Carstairs deprivation category ${ }^{24}$} \\
\hline 1 (affluent) & 72.9 (13 270/18 204) & 1.00 & 1.00 & $75.0(15$ 188/20 254) & 1.00 & 1.00 \\
\hline 2 & 70.8 (28 516/40 265) & $0.92(0.88$ to 0.96$)$ & 0.92 (0.87 to 0.96$)$ & 73.5 (32 484/44 178) & 0.89 (0.85 to 0.93 ) & 0.88 (0.84 to 0.92) \\
\hline 3 & $68.0(53981 / 79411)$ & $0.91(0.87$ to 0.96$)$ & 0.92 (0.88 to 0.96$)$ & 71.4 (63 187/88 522) & 0.91 (0.87 to 0.95$)$ & 0.90 (0.86 to 0.94$)$ \\
\hline 4 & $69.0(63492 / 92$ 067) & 0.88 (0.84 to 0.92$)$ & 0.89 (0.85 to 0.93 ) & 72.0 (72 969/10 1340) & $0.87(0.83$ to 0.90$)$ & 0.86 (0.82 to 0.90$)$ \\
\hline 5 & $66.3(29483 / 44$ 457) & 0.85 (0.81 to 0.89$)$ & 0.86 (0.82 to 0.90$)$ & 71.0 (33 982/47 853) & 0.83 (0.79 to 0.87$)$ & 0.82 (0.78 to 0.86$)$ \\
\hline 6 & 64.3 (23 333/36 287) & $0.77(0.73$ to 0.81$)$ & 0.79 (0.75 to 0.83 ) & 68.1 (26 235/38 547) & 0.78 (0.75 to 0.82$)$ & 0.78 (0.74 to 0.82$)$ \\
\hline 7 (deprived) & $61.2(10242 / 16$ 732) & 0.72 (0.68 to 0.77 ) & 0.75 (0.70 to 0.80$)$ & $66.8(11781 / 17$ 636) & 0.71 (0.67 to 0.75 ) & 0.72 (0.68 to 0.76$)$ \\
\hline \multicolumn{7}{|l|}{ Practice level $^{a}$} \\
\hline \multicolumn{7}{|l|}{ List-size quartile } \\
\hline Q1 (512-2795) & 72.3 (19 478/26 959) & 1.00 & 1.00 & 72.7 (21 990/30 229) & 1.00 & NS \\
\hline Q2 (2796-4789) & 68.6 (39 733/57 914) & 0.82 (0.67 to 1.00 ) & 0.83 (0.68 to 1.02 ) & 72.3 (45 906/63 498) & 0.93 (0.84 to 1.03 ) & \\
\hline Q3 (4790-7606) & 66.9 (63 332/94 640) & 0.75 (0.62 to 0.92 ) & $0.74(0.60$ to 0.91$)$ & 71.5 (73 646/102 960) & 0.91 (0.82 to 1.00$)$ & \\
\hline Q4 (7607-21 440) & 67.5 (99 774/147 910) & $0.76(0.62$ to 0.94$)$ & $0.76(0.62$ to 0.94$)$ & 70.7 (114 284/161 643) & 0.89 (0.80 to 0.98 ) & \\
\hline \multicolumn{7}{|l|}{ Training practice } \\
\hline No & 67.8 (123 255/181 906) & 1.00 & NS & 71.9 (142 265/197 861) & 1.00 & NS \\
\hline Yes & 68.1 (95 273/139 859) & 0.99 (0.85 to 1.15 ) & & 70.9 (109 349/154 195) & 0.95 (0.88 to 1.03 ) & \\
\hline \multicolumn{7}{|l|}{ Contracta $^{\mathrm{a}}$} \\
\hline GMS & 68.3 (196 079/287 270) & 1.00 & NS & 71.5 (224 778/314 400) & 1.00 & NS \\
\hline PMS & 65.1 (22 449/34 495) & 0.94 (0.76 to 1.17$)$ & & 71.3 (26 836/37 656) & 0.94 (0.84 to 1.05 ) & \\
\hline
\end{tabular}

proportion of variation in uptake attributable to variation between practices) in the empty model was 0.111 in 2003-2004 compared with 0.029 in 2006-2007 (data not shown). After adjustment for patient characteristics, the median OR for two patients randomly selected from different practices fell from $2.13(95 \% \mathrm{Cl}=2.00$ to 2.26$)$ to $1.44(95 \% \mathrm{Cl}=$ 1.40 to 1.49 ) (data not shown).

\section{DISCUSSION}

\section{Summary}

Overall, influenza-immunisation uptake rose across all target and socioeconomic groups between 2003-2004 and 2006-2007. and differences between practices were significantly reduced. However, inequalities by socioeconomic deprivation and age persisted. People living in more deprived areas were less likely than their wealthier counterparts to be immunised in both the 2003-2004 and 2006-2007 seasons; likewise younger patients were less likely to be immunised compared with older people.

\section{Strengths and limitations}

This study is observational in design and, therefore, it is not possible to ascribe the increased uptake of influenza immunisation to the QOF alone; the QOF is only one policy among many that affected uptake, which, it should be noted, had been rising before 2004.3,14,26 However, it is notable that the largest increases in immunisation uptake were in patients for whom the QOF provided additional financial incentives. This is consistent with the QOF contributing significantly to changes in practice processes; but due to important unmeasured variables, confounding cannot be excluded.

Although practices received a financial incentive based on recording immunisation in both years, and were incentivised to maintain a register for all of the chronic conditions included from April 2004 
onwards, the study relied on routine clinical data. Reassuringly, overall uptake measured in this study is very close to previously reported national data for patients aged $\geq 65$ years $172.3 \%$ in this study versus $72.5 \%$ across Scotland in 2003-2004 and $75.6 \%$ versus $75.2 \%$ in $2006-2007$ ), which is consistent with the recording of influenza immunisation being accurate in both the 2003-2004 and 2006-2007 seasons. ${ }^{3}$ In addition, the dataset is truly representative of the wider population, with representation of those populations which have higher levels of deprivation. ${ }^{21}$

\section{Comparison with existing literature}

Most previous studies examining influenzaimmunisation uptake have used smaller datasets or are based on self-report in national surveys. ${ }^{13,26,27}$ Coupland et al analysed uptake using data from 413 practices in the QRESEARCH database; however, their time series ended just after the first year of the QOF and the chronic diseases examined did not fully match with the QOF. ${ }^{14}$ To the authors' knowledge, this is the first study that has examined changes in uptake of influenza immunisation and inequalities after implementation of the QOF.

In contrast to the two most significant previous UK studies examining socioeconomic inequalities in care in the first 3 years of QOF implementation, 19,20 this study found a persistent social gradient. Ashworth et al found that a 1.7\% gap between mean blood pressure recording levels in 2004-2005 in practices in the least and most deprived quintiles narrowed to $0.2 \%$ in the first 3 years of the QOF. ${ }^{19}$ Similarly, using a composite of 48 clinical activity indicators, Doran et al found that differences in median achievement narrowed from $4.0 \%$ to $0.8 \%$ over the same time period. ${ }^{20}$

There are several reasons why this study may have found different results. The impact of the QOF on inequalities may depend on the care being examined. For example, reductions in inequalities would plausibly be greater for simple process measures ${ }^{28}$ that are under more control of practices, than for more complex processes that are harder to deliver opportunistically (such as eye screening for patients with diabetes) or are those that are time dependent (such as influenza immunisation). This implies that composite measures may, potentially, conceal persisting inequalities for particular kinds of care, and analyses based on composites should also examine changes for individual measures.
In addition, this study used patient-level data, whereas the two previous studies were ecological practice-level analyses, where practice socioeconomic status was based on the practice postcode. Using practice postcode rather than an aggregate of patient-postcode data in practice-level analyses has been shown to underestimate the degree of socioeconomic inequality found in patients ${ }^{29}$ and, more generally, ecological analysis is known to be an unreliable method for assessing inequalities at individual level. As with previous ecological analyses, differences between practices reduced in this study, but socioeconomic differences between patients were persistent.

Consistent with this, a recently published systematic review identified three studies that used patient-level data to examine socioeconomic inequalities after implementation of the QOF.30 McGovern et al examined changes in $\mathrm{CHD}$ management between 2004 and 2005, and found that, compared with their more affluent counterparts, patients in the most deprived areas were less likely to have their blood pressure measured and receive betablockers or influenza immunisation, although they were more likely to receive antiplatelets and angiotensin-converting enzyme inhibitors. ${ }^{31}$

Simpson et al used a similar study design to examine the impact of the QOF on stroke care 1 year after contract implementation. They found that significant differences persisted between patients in the areas of most and least deprivation, with patients with stroke in the most deprived areas being less likely to have their smoking status or blood pressure recorded. ${ }^{32}$ Further, Millet et al found that the proportion of patients with diabetes with documented smokingcessation advice increased dramatically (from $48 \%$ in 2003 to $83.5 \%$ in 2005), and that the prevalence of smoking had decreased significantly among all socioeconomic groups in the first year of implementation of the QOF.33

The findings of this study are, therefore, consistent with other patient-level analyses, showing that socioeconomic inequalities are persistent for some (but not all) important indicators of quality. As such, ecological or composite indicator analyses showing reducing socioeconomic inequalities should be confirmed by patientlevel analyses and careful examination of individual indicators.

More generally, although inequalities in influenza immunisation were persistent, this study did not find evidence to support 
Victora et al's 'inverse-equity' hypothesis that improving quality will initially widen inequalities. ${ }^{34}$ Rather, immunisation uptake increased for all groups of patients and gaps narrowed, although not significantly in terms of socioeconomic inequalities. In the same vein, the findings do not support concerns expressed in the US that pay-forperformance systems like the QOF will widen inequalities, ${ }^{35}$ although this conclusion could depend, in part, on the QOF payment-system design, where the ability to exception-report means practices are not financially penalised for serving 'harder-to-reach' populations. ${ }^{36}$ However, there was no evidence that socioeconomic differences in uptake were reduced after implementation of the QOF.

\section{Implications for research and practice}

The National Audit Office has proposed that there is a need for a mix of QOF indicators and payment weightings to encourage a more interventionist approach among GP practices who have not engaged with their at-risk patients,' but there is relatively little evidence to guide how best to do this. ${ }^{37}$ Although uptake in older people achieved by the UK general practice-led InfluenzaImmunisation Programme is consistently in the top three of countries that are members of the Organisation for Economic Cooperation and Development, achieving higher uptake in younger people in at-risk groups and among the less affluent might require modification, or alternative forms, of service provision. ${ }^{38}$ With regard to younger people, implementing and evaluating the efficacy of enhancing delivery through occupational services or area-based services offering more out-of-hours appointments would be valuable.

Within general practice, further work is needed to understand better how highperforming practices in areas of deprivation organise the effective delivery of care, and how pay-for-performance systems like the QOF can better contribute to addressing persistent health inequalities; for example, by weighting payment according to socioeconomic status where inequalities are persistent. 


\section{REFERENCES}

1. Scottish Intercollegiate Guidelines Network. Community management of lower respiratory tract infection in adults. SIGN Guideline 59. Edinburgh: Scottish Intercollegiate Guidelines Network, 2002

2. Nicholson KG. Impact of influenza and respiratory syncytial virus on mortality in England and Wales from January 1975 to December 1990. Epidemiol Infect 1996; 116(1): 51-63.

3. Salisbury D, Ramsay M, Noakes K (eds). Immunisation against infectious disease. London: The Stationery Office, 2006.

4. Nichol KL. The efficacy, effectiveness and cost-effectiveness of inactivated influenza virus vaccines. Vaccine 2003; 21(16): 1769-1775

5. Jefferson T, Di Pietrantonj C, Al-Ansary LA, et al. Vaccines for preventing influenza in the elderly. Cochrane Database Syst Rev 2010; (2): CD004876.

6. Govaert TM, Thijs CT, Masurel N, et al. The efficacy of influenza vaccination in elderly individuals. A randomized double-blind placebo-controlled trial. JAMA 1994; 272(21): 1661-1665.

7. Mangtani $P$, Cumberland $P$, Hodgson $C$, et al. A cohort study of the effectiveness of influenza vaccine in older people, performed using the United Kingdom general practice research database. J Infect Dis 2004; 190(1): 1-10.

8. Armstrong BG, Mangtani P. Fletcher A, et al. Effect of influenza vaccination on excess deaths occurring during periods of high circulation of influenza: cohort study in elderly people. BMJ 2004; 329(7467): 660.

9. Poole PJ, Chacko EE, Wood-Baker RW, Cates CJ. Influenza vaccine for patients with chronic obstructive pulmonary disease. Cochrane Database Syst Rev 2006 (1): CD002733

10. Cates CJ, Jefferson TO, Rowe BH. Vaccines for preventing influenza in people with asthma. Cochrane Database Syst Rev 2008; (2): CD000364.

11. Thomas RE, Jefferson T, Lasserson TJ. Influenza vaccination for healthcare workers who work with the elderly. Cochrane Database Syst Rev 2010; (2): CD005187.

12. Thomas DR, Mason BW, Beer L, et al. Surveillance of influenza immunisation uptake in people aged under 65 years with chronic disease. Vaccine 2006; 24(49-50): 7027-7029

13. Blank PR, Freiburghaus AU, Schwenkglenks M, Szucs TD. Trends in influenza vaccination coverage rates in the United Kingdom over six seasons from 2001/02 to 2006/07. Euro Surveill 2008; 13(43): 11-17.

14. Coupland C, Harcourt S, Vinogradova Y, et al. Inequalities in uptake of influenza vaccine by deprivation and risk group: time trends analysis. Vaccine 2007; 25(42): 7363-7371.

15. Gakidou E, Nordhagen S, Obermeyer Z. Coverage of cervical cancer screening in 57 countries: low average levels and large inequalities. PLoS Med 2008; 5(6): 863-868.

16. Weller D, Coleman D, Robertson R, et al. The UK colorectal cancer screening pilot: results of the second round of screening in England. Br J Cancer 2007; 97(12): 1601-1605.

17. Tollitt J, Jain A, Astley S. Health Inequalities in breast cancer screening. Breast Cancer Research 2008; 10(Suppl 2): P57.

18. Reading R, Colver A, Openshaw S, Jarvis S. Do interventions that improve immunisation uptake also reduce social inequalities in uptake. BMJ 1994; 308(6937): 1142-1144

19. Ashworth M, Medina J, Morgan M. Effect of social deprivation on blood pressure monitoring and control in England: a survey of data from the quality and outcomes framework. BMJ 2008; 337: a2030.

20. Doran T, Fullwood C, Kontopantelis E, Reeves D. effect of financial incentives on inequalities in the delivery of primary clinical care in England: analysis of clinical activity indicators for the quality and outcomes framework. Lancet 2008; 372(9640): 728-736

21. Millett C, Netuveli G, Saxena S, Majeed A. Impact of pay for performance on ethnic disparities in intermediate outcomes for diabetes: a longitudinal study. Diabetes Care 2009: 32(3): 404-409.

22. Millett C, Gray J, Bottle A, Majeed A. Ethnic disparities in blood pressure management in patients with hypertension after the introduction of pay for performance. Ann Fam Med 2008; 6(6): 490-496.

23. Elder R, Kirkpatrick M, Ramsay W, et al. Measuring quality in primary medical services using data from SPICE. Edinburgh: Information and Statistics Division, NHS National Services Scotland, 2007.

24. Carstairs V, Morris R. Deprivation and health in Scotland. Aberdeen: Aberdeen University Press, 1991.

25. Larsen K, Merlo J. Appropriate assessment of neighbourhood effects on individual health: integrating random and fixed effects in multilevel logistic regression. Am J Epidemiol 2005; 161(1): 81-88.

26. Breeze E, Mangtani P. Fletcher AE, et al. Trends in influenza vaccination uptake among people aged over 74 years, 1997-2000: survey of 73 general practices in Britain. BMC Fam Pract 2004; 5: 8.

27. Joseph C, Goddard N, Gelb D. Influenza vaccine uptake and distribution in England and Wales using data from the General Practice Research Database, 1989/90-2003/04. J Public Health 2005; 27(4): 371-377.

28. Guthrie B, Emslie-Smith A, Morris A. Which people with type 2 diabetes achieve good control of intermediate outcomes? population database study in a UK region. Diabet Med 2009; 26(12): 1269-1276.

29. McLean G, Guthrie B, Watt G, et al. Practice postcode versus patient population: a comparison of data sources in England and Scotland. Int J Health Geogr 2008; 7: 37

30. Alshamsan R, Majeed A, Ashworth M, et al. Impact of pay for performance on inequalities in health care: systematic review. J Health Serv Res Policy 2010; 15(3): 178-184.

31. McGovern MP, Boroujerdi MA, Taylor MW, et al. The effect of the UK incentive-based contract on the management of patients with coronary heart disease in primary care. Fam Pract 2008; 25(1): 33-39.

32. Simpson CR, Hannaford PC, Lefevre K, Williams D. Effect of the UK incentivebased contract on the management of patients with stroke in primary care. Stroke 2006; 37(9): 2354-2360.

33. Millet C, Gray J, Saxena S, et al. Impact of a pay-for-performance incentive on support for smoking cessation and on smoking prevalence among people with diabetes. CMAJ 2007; 176(12): 1705-1710.

34. Victora CG, Vaughan JP, Barros FC, et al. Explaining trends in inequities: evidence from Brazilian child health studies. Lancet 2000; 356(9235): 1093-1098.

35. Casalino LP, Elster A, Eisenberg A, et al. Will pay-for-performance and quality reporting affect health care disparities? Health Aff (Millwood) 2007; 26(3): w405-14

36. Friedberg MW, Safran DG, Coltin $\mathrm{K}$, et al. Paying for performance in primary care: potential impact on practices and disparities. Health Aff (Millwood) 2010; 29(5): 926-932.

37. National Audit Office. Tackling inequalities in life expectancy in areas with the worst health and deprivation. London: National Audit Office, 2010.

38. Organisation for Economic Co-operation and Development. Health data 2010: statistics and indicators. Paris: Organisation for Economic Co-Operation and Development, 2010. http://www.oecd.org/health/healthdata laccessed 13 Jun 2011). 